\title{
Review of the genus classification of Abiinae (Cimbicidae, Hymenoptera)
}

\author{
Lars VILHELMSEN ${ }^{1, *} \&$ Akihiko SHINOHARA ${ }^{2}$ \\ ${ }^{1}$ Natural History Museum of Denmark, SCIENCE, University of Copenhagen, \\ Universitetsparken 15, DK-2100, Denmark. \\ ${ }^{2}$ Department of Zoology, National Museum of Nature and Science, 4-1-1 Amakubo, \\ Tsukuba, Ibaraki 305-0005, Japan. \\ ${ }^{*}$ Corresponding author: lbvilhelmsen@snm.ku.dk \\ 2Email: shinohar@kahaku.go.jp \\ ${ }^{1}$ urn:1sid:zoobank.org:author:C1C38989-562D-4490-B91F-C6C7AA4E5E4A \\ ${ }^{2}$ urn:1sid:zoobank.org:author:C7382A9B-948F-479B-BEE7-848DAFECD3BA
}

\begin{abstract}
Abiinae is the second-largest subfamily in Cimbicidae, a small family of true sawflies (Tenthredinoidea). The subfamily is adequately defined, but the generic classification has been unstable. Currently, only two genera are regarded as valid: Abia Leach, 1817 and Allabia Semenov \& Gussakovskij, 1937. We evaluate the generic classification of Abiinae in a phylogenetic context. A total of 32 species (out of 57 described for the subfamily), including the type species of Allabia, Allabia infernalis (Semenov, 1896), are scored for 150 adult morphological characters. Results show some resolution, but only few clades can be circumscribed by consistent character combinations. Most of the characters that have previously been used to define genera are not congruent; consequently, most suggested genus definitions appear to be random character state combinations and few natural groups can be identified. For these reasons, we treat Allabia syn. nov. as a junior synonym of Abia and make the following additional taxonomic changes: Abia infernalis Semenov, $1896 \mathrm{comb}$. rev. and Abia malaisei (Semenov \& Gussakovskij, 1937) syn. nov. For the purpose of long-term stability of the classification of Abiinae, we recommend recognizing only one genus, Abia, within the subfamily.
\end{abstract}

Keywords. 'Symphyta', Tenthredinoidea, morphology, phylogeny.

Vilhelmsen L. \& Shinohara A. 2020. Review of the genus classification of Abiinae (Cimbicidae, Hymenoptera). European Journal of Taxonomy 608: 1-23. https://doi.org/10.5852/ejt.2020.608

\section{Introduction}

The Abiinae is the second-largest subfamily in the Cimbicidae, comprising 57 extant species (Hara \& Shinohara 2017; Vilhelmsen 2019). The members of the subfamily are on average smaller than their putative sister group, the Cimbicinae, which may reach body lengths of $3 \mathrm{~cm}$. Abiinines usually measure between 1 and $2 \mathrm{~cm}$ in body length (Figs 1-4), overlapping with the size of the smaller species of Cimbicinae. The Abiinae, like the Cimbicinae, occur in the Holarctic and Oriental regions, with the 
highest diversity in the eastern part of their area of distribution; only five species are recorded from the Nearctic Region, including two introduced. Host plants of the larvae (to the extent that they are known) belong to the families Aquifoliaceae, Caprifoliaceae, Dipsacaceae and Lardizabalaceae (Liston et al. 2014).

The Abiinae were consistently retrieved as monophyletic in Vilhelmsen (2019), with moderate support. Putative autapomorphies for the subfamily are having the eyes converging dorsally, extending above the ocelli (Figs 5-6; in the males, the eyes almost abut on top of the head), and the presence of a median carina on abdominal tergum 1. In addition, Abiinae are the only Cimbicidae to have a well-developed epistomal sulcus and no sclerotizsation between the foramen magnum and oral foramen in the head, but these traits are probably plesiomorphic.

Morphological diversity of the Abiinae is smaller than that of Cimbicinae, which currently comprise eight extant genera (Vilhelmsen 2019). Presently, only two genera are recognized in Abiinae: Abia Leach, 1817 contains most of the species; Allabia Semenov \& Gussakovskij, 1937 the two remaining. Previously, the genera Zaraea Leach, 1817 and Orientabia Malaise, 1934 were widely recognized. In addition, Abia (Parabia) Semenov, 1891, Abia (Aenoabia) Kangas, 1946 and Zaraea (Auroabia) Kangas, 1946 had been introduced but not widely implemented; Aenoabia has also been treated as a separate genus (Viitasaari 1990). Finally, the fossil genus Procimbex Hong, 1984 is currently considered a synonym of Abia (Zhang 1989; Blank et al. 2009).

Leach (1817) described both Abia and Zaraea, separating them by the antennal club containing three (Fig. 6F) or two (Fig. 5C) antennomeres, respectively. The antennal club is one of the diagnostic features of Cimbicidae and may contain between one and (rarely) five antennomeres, see Wei et al. (2012) and Vilhelmsen (2019). Orientabia was defined by Malaise (1934) as having the subapical tooth of the tarsal claw more developed than the apical tooth; the opposite of Abia according to him. Malaise (1934) did not provide a full description of Orientabia, only some supplementary notes on the female of Abia egregia Kuznetzov-Ugamskij, 1927 which Malaise designated as the type species of Orientabia; all species eventually placed in this genus are distributed in the east Palearctic and Oriental regions. Takeuchi (1939) used the distinctly emarginated ventral margin of the clypeus as an additional character to define Orientabia.

Semenov \& Gussakovskij (1937) designated Abia infernalis Semenov, 1896 (Fig. 7) from Sichuan Province, P.R. China (Oriental) as the type species of Allabia. In addition, they included the newly described species Allabia malaisei Semenov \& Gussakovskij, 1937, from Gansu Province (east Palearctic); both species were described from a single male. Allabia was defined by Semenov \& Gussakovskij (1937) by a combination of characters. It differs from Orientabia in the distance of the eyes dorsally in the male being larger (separated by more than width of antennal flagellum; Fig. 7C) than in Orientabia (eyes almost abutting; Fig. 6E) and the subapical tarsal claw being less developed in Allabia. Furthermore, Allabia and Orientabia are separated from Abia and Zaraea by having the clypeus emarginated, the body less metallic in color and being more hairy.

A number of characters have been employed by various authors to separate the genera in Abiinae: body coloration (Gussakovskij 1947; Benson 1951; Quinlan \& Gauld 1981; Viitasaari 1990; Zhelochovtsev et al. 1994); length of hairs on body (Benson 1946, 1951; Gussakovskij 1947; Zhelochovtsev et al. 1994, translated from the original Russian by Zhelochovtsev \& Zinovjev 1988 [not consulted]); distance between eyes dorsally in males (Gussakovskij 1947; Wei et al. 2012); configuration of ventral margin of clypeus (Takeuchi 1939; Lee \& Jung 1999; Wei et al. 2012); proportions of $3^{\text {rd }}$ and $4^{\text {th }}$ antennomeres (Konow 1887); antennal club with two or three antennomeres (Konow, 1887); antennal color (Viitasaari 1990); mesopleural sculpture (Benson 1946); length of hind tarsomere 1 relative to tarsomeres 2 and 3 
(Benson 1946, 1951; Quinlan \& Gauld 1981; Viitasaari 1990); configuration of tarsal claws (Malaise 1934; Takeuchi 1939; Benson 1946, 1951; Quinlan \& Gauld 1981; Zhelochovtsev et al. 1994; Lee \& Jung 1999; Wei et al. 2012); fore wing infuscation pattern (Viitasaari 1990); having the $1^{\text {st }}$ abdominal tergum pale in the females (Kangas 1946; Viitasaari 1990); occurrence of depressions with hairy patches on abdominal terga in males (Semenov 1891; Kangas 1946; Quinlan \& Gauld 1981; Viitasaari 1990; Zhelochovtsev et al. 1994); configuration of sawteeth in the ovipositor (Kangas 1946); configuration of the male genitalia (Kangas 1946).

From these efforts, no consensus has emerged on how to define genera in Abiinae in a way that is widely applicable. All of the publications listed above are limited in geographic scope, focusing mostly on single countries in either the western Palearctic (e.g., Benson 1951; Quinlan \& Gauld 1981; Viitasaari 1990; Zhelochovtsev et al. 1994) or eastern Palearctic/Oriental regions (e.g., Takeuchi 1939; Lee \& Jung 1999; Wei et al. 2012). The situation in the Nearctic region is much simpler, the small abiine fauna having exclusively been placed in Zaraea (e.g., Ross 1937; Smith 1979; Goulet 1992), at least until recently. The classification scheme for Abiinae, i.e., the Abia/Zaraea dichotomy, initially developed for the western Palearctic seems to have been adapted to the more diverse eastern Palearctic/Oriental fauna by adding new genera (i.e., Allabia and Orientabia) to deal with specimens displaying new character combinations. The lack of stability in the generic classification of Abiinae is reflected by most of the species included in the present study (approx. 3/4; see Table 1) having been recombined at least once in the two centuries since Abia and Zaraea were recognized.

Noticing the variability of many of the characters used to define genera in Abiinae, Taeger (1998) decided to recognize only Abia in his treatment of the German fauna of Cimbicidae. Liston et al. (2014) produced sequence data for a number of western Palearctic Abiinae, including the type species of both Abia and Zaraea; they did not find evidence for upholding Zaraea either. Hara \& Shinohara (2017) surveyed the characters primarily used to identify Orientabia, i.e., the configuration of the clypeus and the tarsal claw structure; they found these traits to be highly variable across a substantial taxon sample of both Abia and Orientabia and synonymized the latter with the former. Vilhelmsen (2019) in his morphological phylogenetic analyses of the Cimbicidae sampled 30 taxa of Abiinae, including a number of species formerly placed in either Orientabia or Zaraea. The Abiinae were consistently retrieved as monophyletic, but with poor internal resolution. Despite including a number of the characters mentioned above, Vilhelmsen (2019) did not retrieve Orientabia or Zaraea; Allabia was not included in the taxon sample and in general seems to have been little studied since it was described.

In the present paper, we expand the morphological data set assembled for Vilhelmsen (2019) and analyze it to explore the classification of Abiinae and more of the characters that have previously been employed in separating the genera of the subfamily. Crucially, we include the type material of Allabia infernalis to evaluate the status of Allabia.

\section{Material and methods}

\section{Taxon sample}

In addition to the taxa in Vilhelmsen (2019), the following taxa were scored and included in the

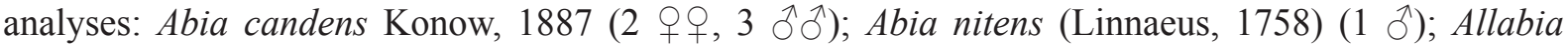
infernalis (Semenov, 1896) (holotype, Ôं; deposited in the Zoological Institute, Russian Academy of Sciences, St. Petersburg [ZIN]). We were unable to examine the holotype of Allabia malaisei Semenov \& Gussakovskij, 1937; it is deposited in the Naturhistoriska Riksmuseet, Stockholm, Sweden, but was on loan at the time of the request. For a full list of Abiinae material examined for this study, see Table 1. Included is also a count of combinations registered for each species in Taeger et al. (2018); synonyms, misspellings, combinations in genera outside Abiinae etc. are not included in this tabulation. 
Table 1. Taxa of Abiinae examined. Abbreviations: Ab = Abia; Ae = Aenoabia; Al = Allabia; $A u=$ Auroabia; Or $=$ Orientabia; $Z a=$ Zaraea.${ }^{*}$ Combinations at the genus or subgenus level listed under species epithet from Taeger et al. (2018; see also 'Material and methods' section). Original combination underlined. ${ }^{1}$ Originally placed in Tenthredo Linnaeus, 1758.

\begin{tabular}{|c|c|c|c|}
\hline Species & Author, year & Region & Combinations* \\
\hline Abia akebii & (Takeuchi, 1931) & Palearctic & $A b, \underline{Z a}$ \\
\hline Abia alutacea & (Malaise, 1939) & Oriental & $A b, \underline{Z a}$ \\
\hline Abia americana & (Cresson, 1880) & Nearctic & $A b, \underline{Z a}$ \\
\hline Abia aurulenta & Sichel, 1856 & Palearctic & $\underline{A b}, A u, Z a$ \\
\hline Abia berezowskii & Semenov, 1896 & Palearctic & $\underline{A b}$ \\
\hline$\underline{\text { Abia candens }}$ & Konow, 1887 & Palearctic & $\underline{A b}, Z a$ \\
\hline Abia coreana & Takeuchi, 1927 & Palearctic & $\underline{A b}, O r$ \\
\hline Abia fasciata & (Linnaeus, 1758) & Palearctic & $A b, Z a^{1}$ \\
\hline Abia formosa & Takeuchi, 1927 & Oriental & $\underline{A b}$ \\
\hline Abia fulgens & Zaddach, 1863 & Palearctic & $\underline{A b}$ \\
\hline Abia gribodoi & Konow, 1895 & Palearctic & $\underline{A b}, Z a$ \\
\hline Abia imperialis & Kirby, 1882 & Oriental & $\underline{A b}$ \\
\hline Allabia infernalis & (Semenov, 1896) & Palearctic & $\underline{A b}, A l$ \\
\hline Abia inflata & (Norton, 1861) & Nearctic & $A b, \underline{Z a}$ \\
\hline Abia iridescens & Marlatt, 1898 & Oriental & $\underline{A b}, O r$ \\
\hline Abia japonica & Cameron, 1887 & Palearctic & $\underline{A b}, O r$ \\
\hline Abia kennicotti & Norton, 1867 & Nearctic & $\underline{A b}, Z a$ \\
\hline Abia kozhevnikovi & Zhelochovtsev, 1924 & Palearctic & $\underline{A b}, A e, Z a$ \\
\hline Abia lewisii & Cameron, 1887 & Palearctic & $\underline{A b}, Z a$ \\
\hline Abia lonicerae & (Linnaeus, 1758) & Nearctic & $A b, Z a^{1}$ \\
\hline Abia marginata & Mocsáry, 1909 & Palearctic & $\underline{A b}, Z a$ \\
\hline Abia melanocera & Cameron, 1899 & Palearctic & $\underline{A b}$ \\
\hline Abia metallica & Mocsáry, 1909 & Palearctic & $\underline{A b}, A e, Z a$ \\
\hline Abia mutica & Thomson, 1871 & Palearctic & $\underline{A b}, A e, Z a$ \\
\hline Abia nitens & (Linnaeus, 1758) & Palearctic & $A b^{1}$ \\
\hline Abia niui & Wei \& Deng, 1999 & Oriental & $\underline{A b}$ \\
\hline Abia pulcherrima & Mallach, 1930 & Oriental & $\underline{A b}$ \\
\hline Abia relativa & Rohwer, 1910 & Palearctic & $\underline{A b}, O r$ \\
\hline Abia sachalinensis & Takeuchi, 1931 & Palearctic & $\underline{A b}, O r$ \\
\hline Abia sericea & (Linné, 1767) & Palearctic & $A b, Z a^{1}$ \\
\hline Abia triangularis & (Takeuchi, 1931) & Palearctic & $A b, \underline{Z a}$ \\
\hline Abia zhelochovtzevi & (Gussakovskij, 1947) & Palearctic & $A b, \underline{Z a}$ \\
\hline
\end{tabular}


The taxon sample of the present paper encompasses most of the geographical range of the subfamily, and all the genera most commonly recognized are sampled, including the type species for most of these. However, material of Abia egregia Kuznetzov-Ugamskij, 1927, the type species of Orientabia Malaise, 1934, was not available. Taxa outside Abiinae included in the phylogenetic analyses are listed in Vilhelmsen (2019; table S1).

\section{Institutional acronyms}

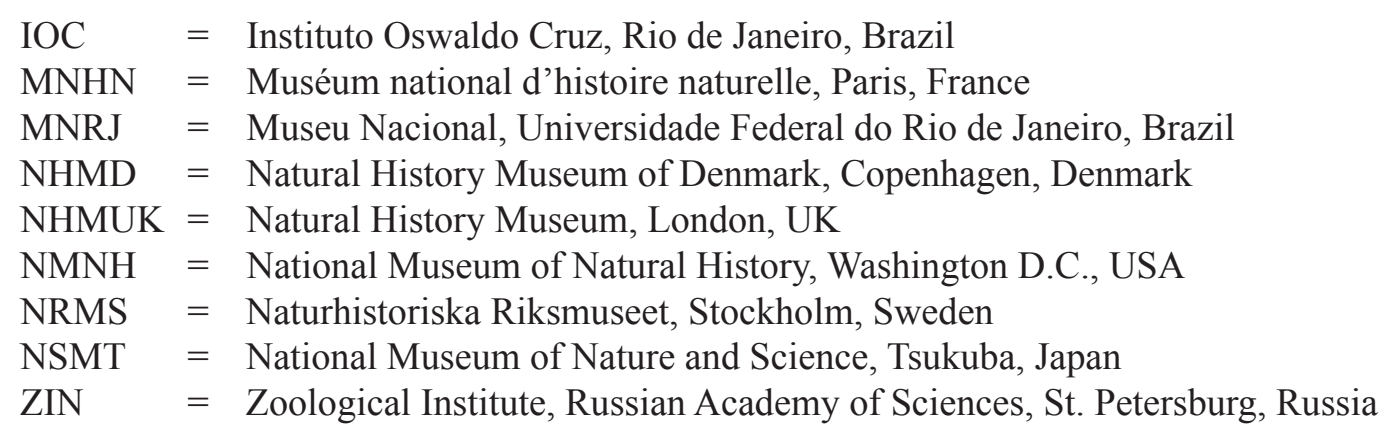

\section{Examination of specimens and imaging}

Scoring of characters was carried out under a Leica M205C dissection microscope. Images of pinned specimens were produced with a Visionary Digital imaging setup with flash lighting and P-51 Camlift Driver ver. 2.6.1 to control the camera. A cylinder of semitransparent plastic was placed around the specimen to disperse the light. Images were stored in Adobe Lightroom 2 and composite images were compiled from stacks with the software Zerene Stacker ver.1.04 by implementing the Pyramidal stacking method (PMax).

\section{Character set}

The new taxa included were scored for the morphological data set of Vilhelmsen (2019, supporting information); the terminology of the present paper follows that of Vilhelmsen (2019). Some of the characters mentioned in the Introduction have not been included, as they were either considered to be too variable or poorly defined to be informative (body pilosity; sculpture on mesopleura) or because they required dissection (ovipositor; male genitalia), material for which was not available for most species. Other characters in the dataset of Vilhelmsen (2019) were amended or changed to accommodate additional variation within Abiinae not initially coded:

- Character 84. Hind leg, length of tarsomere 1: shorter than tarsomeres 2-3 = 0; at least equal to tarsomeres $2-3$ but at most shorter than tarsomeres $2-4=1$; equal to or longer than tarsomeres $2-4$ $=2$ (ordered).

State 0 in Vilhelmsen (2019) was subdivided into state 0 and 1 here, and the character treated as additive.

- Character 124. Abdomen, male T4-7: without depressions on any tergites (Fig. 2E) =0; with depression accommodating hair patch medially in T4-6 (Fig. 2A-B) $=1$; with depression accommodating hair patch medially in T4-7 (Fig. 2D) $=2$ (ordered).

The occurrence of hair patches on the male abdominal tergites was scored as either absent or present in Vilhelmsen (2019). There is some variation in the number of tergites having this feature within Abia; this has been taken into account for the present analyses by subdividing state 1 in Vilhelmsen (2019). 
Additional characters not included in Vilhelmsen (2019) are listed below. These are characters that have at some point been used in various classification schemes at the genus level for Abiinae (see Introduction).

- Character 145. Head, distance between eyes dorsally (male): more than diameter of posterior ocellus $($ Figs $6 \mathrm{~B}, \mathrm{D}, 7 \mathrm{C})=0$; less than diameter of posterior ocellus (Fig. 6A, C, E-F) $=1$.

All taxa outside Abia for which males are available have state 0 .

- Character 146. Head, intertorular groove: absent (Fig. 5C, F) =0; transverse groove present between toruli (Figs 5B, D, 7C) $=1$.

- Character 147. Antenna color, female: more or less equally colored throughout (Fig. 5C-D, F) =0; tip paler than base (Fig. 5B) $=1$; palest in the middle (Fig. 5A) $=2$; base paler than tip $=3$ (Fig. 5E) (unordered).

- Character 148. Antenna color, male: more or less equally colored throughout (Fig. 6A-B) $=0$; tip paler than base (Fig. $6 \mathrm{E})=1$; palest in the middle (Fig. $6 \mathrm{C})=2$; base paler than tip (Fig. 6F) $=3$ (unordered).

- Character 149. Hind leg, tibial color: dark, similar to hind femur (Figs 3F, H, 4A, 7B) =0; pale, lighter than at least basal part of hind femur (Figs 3B, G, 4B-F, H) $=1$.

- Character 150. Fore wing, transverse infuscated band: absent (Figs 1A, E-F, 2C, 7A) =0; present (Figs 1B-D, 2A-B, D, E) $=1$.

This character is treated as different from Character 106, which deals with a longitudinal band extending from base to apex of the anterior part of the wing (Fig. 1C, E). The infuscation coded here is a transverse band extending from anterior to the posterior margin at the level of the pterostigma or proximal to it. A spot which does not reach both margins does not qualify as a band. Both transverse and longitudinal bands may occur in the same taxon (e.g., Abia formosa; Fig. 1C).

\section{Phylogenetic analyses}

The character matrix was assembled in Mesquite ver. 3.6 (Maddison \& Maddison 2018). The dataset was analyzed with TNT ver. 1.5 (Goloboff \& Catalano 2016). The following characters were treated as ordered: $1,5,9,10,12,14,20,21,23,32,63,74,84,87,95,103,104,116,124,125,126,134$. Space for 1000000 trees was reserved in memory. Traditional searches were run for equal (EW) and implied weights (IW) analyses with 10000 replications, saving 100 trees per replication. The root was Blasticotoma. The $k$-values for IW analyses were set to $1-10,15,20$, and 25 in turn. Character evolution was explored in Mesquite. The matrix assembled for the present paper is available from https://figshare.com/articles/Abia2019EJTmatrix/9944126.

\section{Results}

\section{Phylogeny}

The overall topologies retrieved for Cimbicidae across different analytical settings are very similar to those reported in Vilhelmsen (2019). Abiinae are always retrieved as monophyletic and sister to Cimbicinae. The topology for Abiinae is better resolved than in Vilhelmsen (2019), although a large unresolved polytomy persists near the base of the subfamily (Figs 8-10), especially in the EW topology (Fig. 10). Furthermore, few of the retrieved relationships are stable across the range of analytical settings. Allabia infernalis is placed as sister to Abia kennicotti in all IW analyses, this pair being in a 
larger clade with Abia americana, A. lewisii and A. metallica at $k$-values 1-10 (Fig. 8); at $k=15$ and higher, Al. infernalis and A. kennicotti are sister to all other Abiinae (Fig. 9). This position is taken by A. akebii $+($ A. fasciata + A. triangularis) when $k=1-10$ (Fig. 8). Abia aurulenta is the next taxon to branch off when $k=1-10$. A large clade comprising 16 of the included species of Abiinae is consistently retrieved; it is called here the sericea group as A. sericea is nested within it, although its position inside the clade varies considerably. The clade $A$. nitens $+($ A. berezowskii + A. melanocera $)$ is retrieved in most IW analyses with lower $k$ values $(k=1-7)$. Included in the sericea group are also the five taxa previously placed in Orientabia, but never in a single clade; however, at $k=4$ or higher, as well as in the EW topology, four species (all except $A$. iridescens) group together as a 'core Orientabia' clade (Figs 8-10).

\section{Taxonomy}

Order Hymenoptera Linnaeus, 1758

Family Cimbicidae W. Kirby, 1837

Abia Leach, 1817

Zaraea Leach, 1817: 113.

Abia (Parabia) Semenov, 1891: 174.

Orientabia Malaise, 1934: 36.

Allabia Semenov \& Gussakovskij, 1937: 5, syn. nov.

Abia (Aenoabia) Kangas, 1946: 88.

Zaraea (Auroabia) Kangas, 1946: 89.

†Procimbex Hong, 1984: 7.

\section{Type species}

Tenthredo sericea Linné, 1767.

\section{Revised species}

Abia infernalis Semenov, 1896 comb. rev.

Abia malaisei (Semenov \& Gussakovskij, 1937) comb. nov.

Redescription (female; male structures only mentioned when differing from females)

Medium-sized to large sawflies, body length from around $1 \mathrm{~cm}$ to just below $2 \mathrm{~cm}$. Body coloration ranges from green (e.g., Fig. 2D) or blue metallic (Fig. 2A) to more coppery, violet (Figs 1E, 3F) or even blackish-brown with little or no metallic tinge (Figs 1B, 7A-B). Color usually uniform, but a few species (e.g., A. fasciata) with a creamy-white abdominal tergum 1 forming a bright band across the anterior part of the abdomen (Fig. 1B) or even with repeated pale transverse bands (A. kennicotti, Fig. 1F; A. marginata) along parts of the abdomen. Body often hairy, especially head and thorax. Wings mostly hyaline, fore wing often with infuscated transverse band (Fig. 1B) or spot, rarely with anterior part of fore wing completely infuscated (e.g., A. iridescens; Fig. 1E).

HEAD. Eyes converging dorsally, reaching above posterior ocelli; in male eyes close together dorsally, being separated at most by distance slightly above diameter of anterior ocellus (Fig. 6B, D), sometimes almost abutting (Fig. 6E). Toruli in middle of face, approx. halfway between median ocellus and ventral margin of clypeus; intertorular groove present or absent. Epistomal sulcus usually well developed (weakly developed in A. relativa). Ventral margin of clypeus variable, usually straight but sometimes deeply incurved (e.g., A. relativa; Fig. 5F). Genal width variable. Malar space variable, from less than half to about equal to height of clypeus. Occipital carina absent. Sclerotization between occipital and oral foramina absent. Antenna with six or seven antennomeres; antennomere 1 less than $2 \times$ as long 
as wide, antennomere 2 shorter than wide, antennomere 3 at least $1.5 \times$ as long as antennomere 4 , antennomeres 5-6/7 expanded into distinct club. Labrum slightly convex, at least as wide as high, except in A. relativa. Mandibles in both sexes usually shorter than $0.5 \times$ height of head capsule, sometimes longer (e.g., A. relativa; Fig. 5F); left mandible with three teeth, sometimes with serrations (e.g., A. iridescens). Maxilla with stipes usually tapering distally, palp with six palpomeres, inserts close to labial palp. Labial palp with four palpomeres. Postmentum narrow, at least $3 \times$ as long as wide.

Thorax. Pronotum comparatively high medially, without any conspicuous grooves; pronotum fused with anterior margin of mesopleuron from just below anterior thoracic spiracle to ventral corner. Dorsal cervical sclerite absent. Propleuron without lateral projection, propleural sulcus absent, medioventral margins widely separated, posteriorly extended into narrow points. Prosternum laterally extended, fused with propleura at lateral procoxal articulation points, forming narrow bridge; katepisterna absent as independent sclerites. Anterior fore tibial spur straight, simple, not much longer than posterior spur, spurs with blunt membraneous pads apically. Mesonotum with distinct median sulcus and deep notauli; laterophragmal apodeme elongate, extending towards mesofurca; postscutellum absent. No indication of prepectus. Horizontal carina absent laterally on mesopleuron (faint swelling present in A. imperialis); posterior thoracic spiracle visible in lateral view, situated in incurvation in dorsal margin of mesopleuron. Median midcoxal articulations adjacent, only separated by small wedge of cuticle. Mesofurca with mesospina (absent in A. sericea) and elongate anterior and lateral arms. Insertion of mesonoto-metanotal muscle medially on metanotum on small ring-like structure; cenchri at least $3 \times$ as broad as long. Anapleural cleft present, small (absent in A. iridescens). Metapleuron fused with abdominal tergum 1 along dorsal margin; posteroventral metapleural apodeme absent; paracoxal sulcus curving anteriorly, terminating in metapleural sulcus close to anterior margin of metapleuron; metacoxal foramina open dorsally, with slight metapleural inflection laterally. Metafurca with anterior arms variable in length, lateral arms elongate. Hind coxa less than twice as long as wide, median carina or spine absent. Hind femoral ventral spur absent. Hind tibial apical spurs shorter than apical width of tibia. Hind tarsomere 1 shorter than tarsomeres $2-4$, tarsal claws variable, inner tooth absent, short or as large as outer (most common condition when present).

WINGs. Male pterostigma not expanded anteriorly. Vein M joins Sc+R some distance from Rs $+\mathrm{M}$; vein $2 \mathrm{r}-\mathrm{m}$ posteriorly inserts on cell $2 \mathrm{M}$ distally to anterior end of $2 \mathrm{~m}$-cu; vein $1 \mathrm{~m}-\mathrm{cu}$ inserts on Rs $+\mathrm{M}$ some distance from posterior insertion of $2 \mathrm{r}-\mathrm{m}$ (distance $1 \mathrm{~m}-\mathrm{cu}-2 \mathrm{r}-\mathrm{m}$ at least $1 / 3$ distance $\mathrm{M}-1 \mathrm{~m}-\mathrm{cu}$ on $\mathrm{Rs}+\mathrm{M}$ ); posterior anal vein present proximally and distally but discontinuous in the middle. Hind wing cell R1 closed; vein M continuous, separating cells Rs and M, cell M not reaching vein Rs; cross vein 2a absent.

ABDOMEN. Tergum 1 not subdivided medially, median carina present, lateral swelling present, posterior margin more or less straight. Metaphragma continuous medially, of approx. equal height throughout, median foramen present. Lateroterga around abdominal spiracles separated from median terga as demarcated by conspicuous fold. In males of many species (e.g., A. gribodoi, A. relativa, A. sericea), abdominal terga 4-6 or 4-7 with medial depression accommodating hairy patch (Fig. 2A-D). Female cercus usually at least twice as long as wide (shorter in, e.g., A. pulcherrima). Ovipositor apparatus with $1^{\text {st }}$ valvula having longitudinal line, sawteeth symmetric, serrulae present; tip of $1^{\text {st }}$ and $2^{\text {nd }}$ valvulae distinctly curving dorsally (Fig. 3D); ventral margin with tufts of setae along its length, tufts on lobes. 


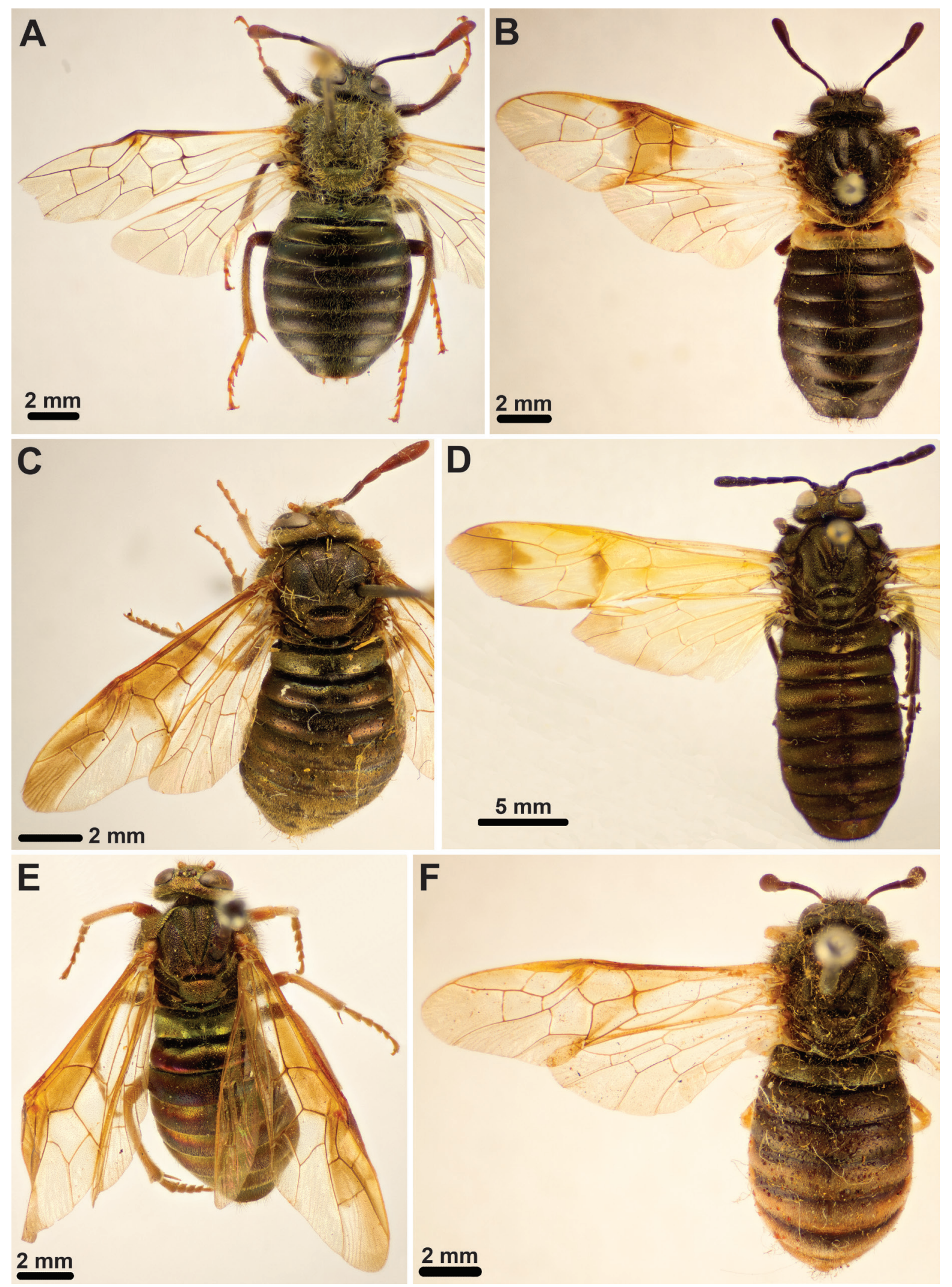

Fig. 1. Habitus dorsal, females. A. Abia coreana Takeuchi, 1927 (NSMT). B. Abia fasciata (Linnaeus, 1758) (NHMD). C. Abia formosa Takeuchi, 1927 (NRMS). D. Abia imperialis Kirby, 1882 (NHMD). E. Abia iridescens Marlatt, 1898 (NSMT). F. Abia kennicotti Norton, 1867 (NHMUK). 


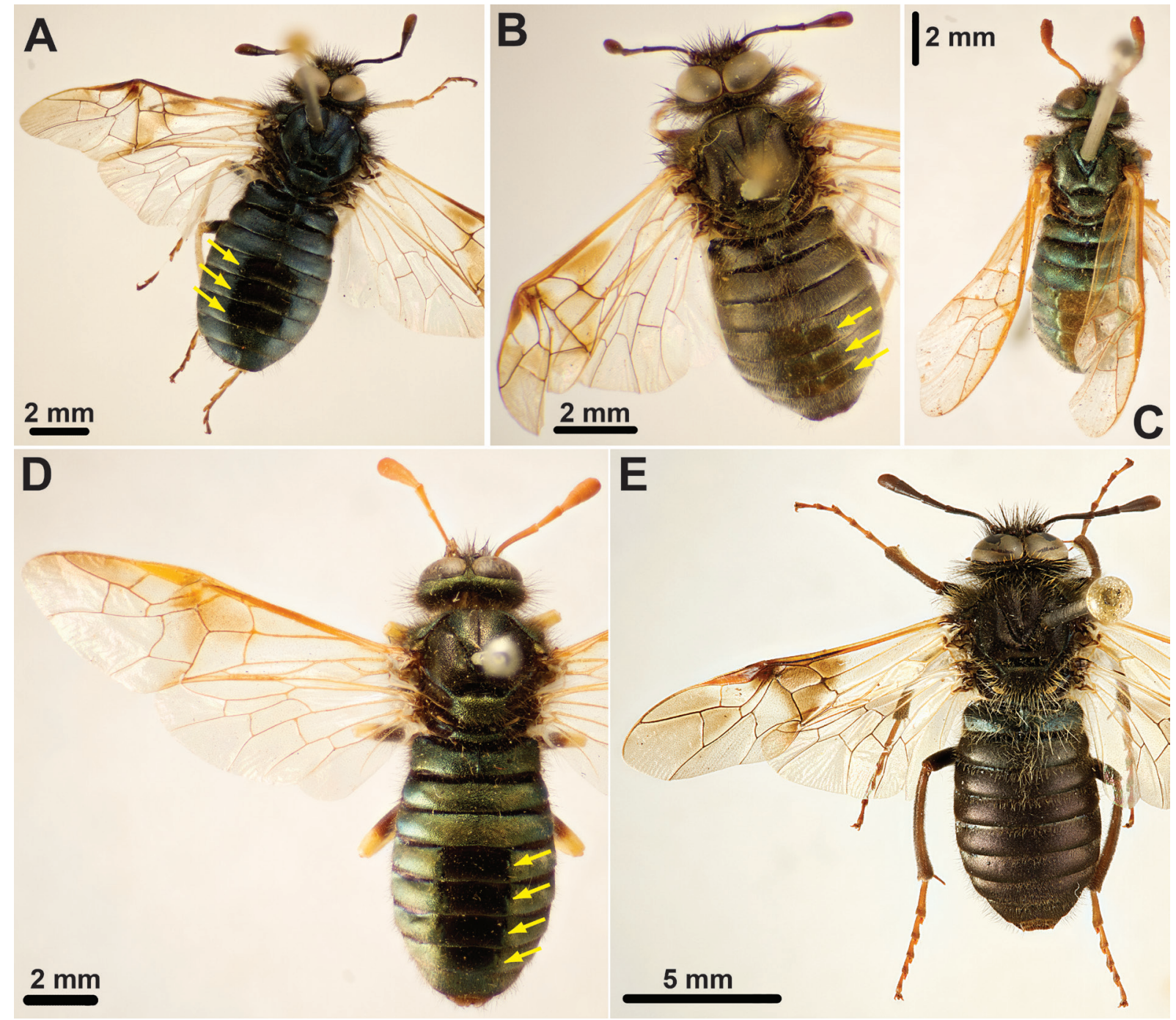

Fig. 2. Habitus dorsal, males. A. Abia lewisii Cameron, 1887 (NSMT). B. Abia metallica Mocsáry, 1909 (NSMT). C. Abia nitens (Linnaeus, 1758) (NHMD). D. Abia sericea (Linné, 1767) (NHMD). E. Abia triangularis (Takeuchi, 1931) (NSMT). Yellow arrows = depressions with hairy patches on abdominal terga. 


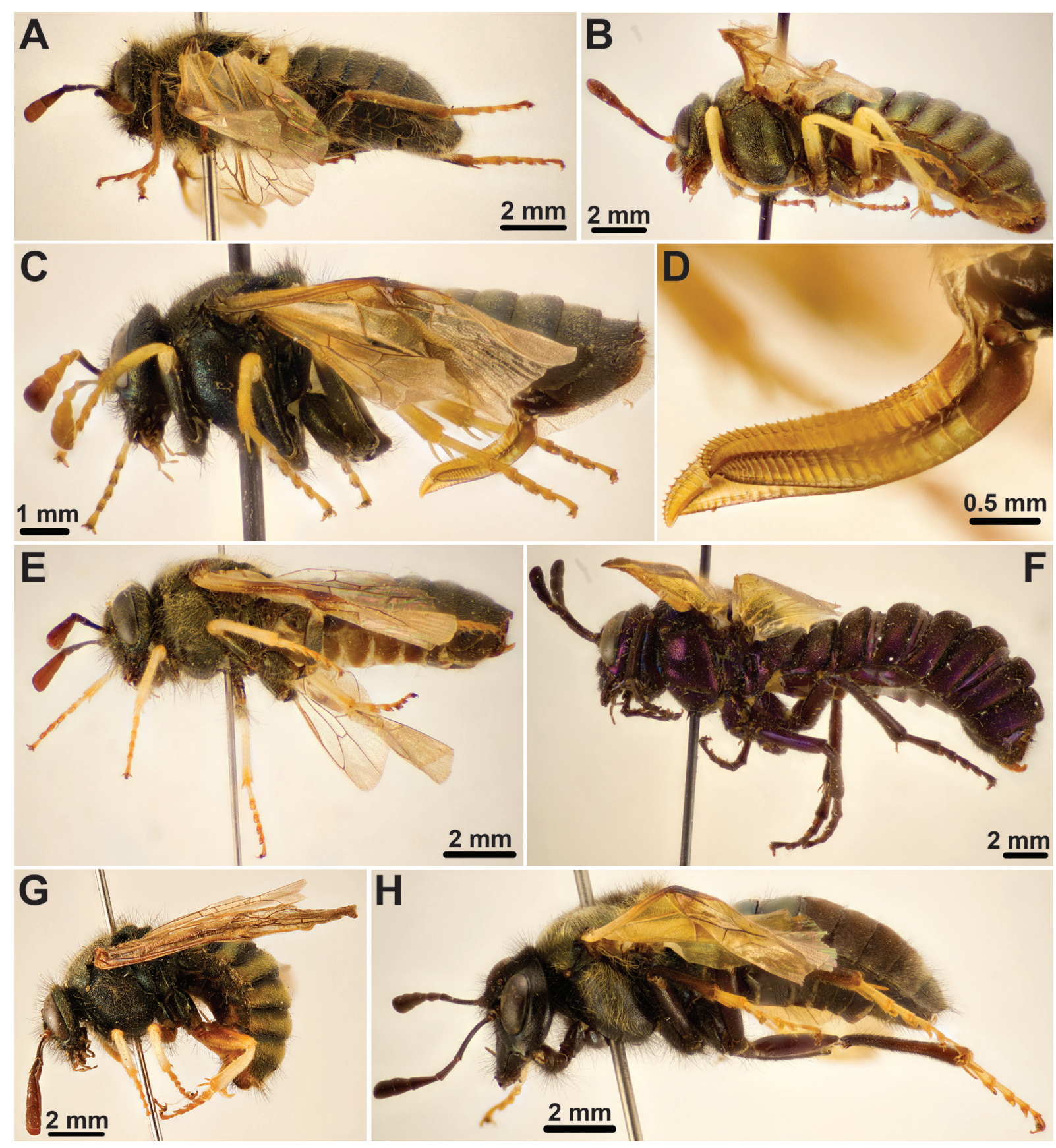

Fig. 3. Habitus lateral, females, except D, which shows ovipositor (upside down). A. Abia akebii (Takeuchi, 1931) (NSMT). B. Abia berezowskii Semenov, 1896 (NRMS). C-D. Abia candens (Konow, 1887) (NHMD). E. Abia metallica Mocsáry, 1909 (NSMT). F. Abia pulcherrima Mallach, 1930 (NRMS). G. Abia niui Wei \& Deng, 1999 (NMNH). H. Abia relativa Rohwer, 1910 (NSMT). 


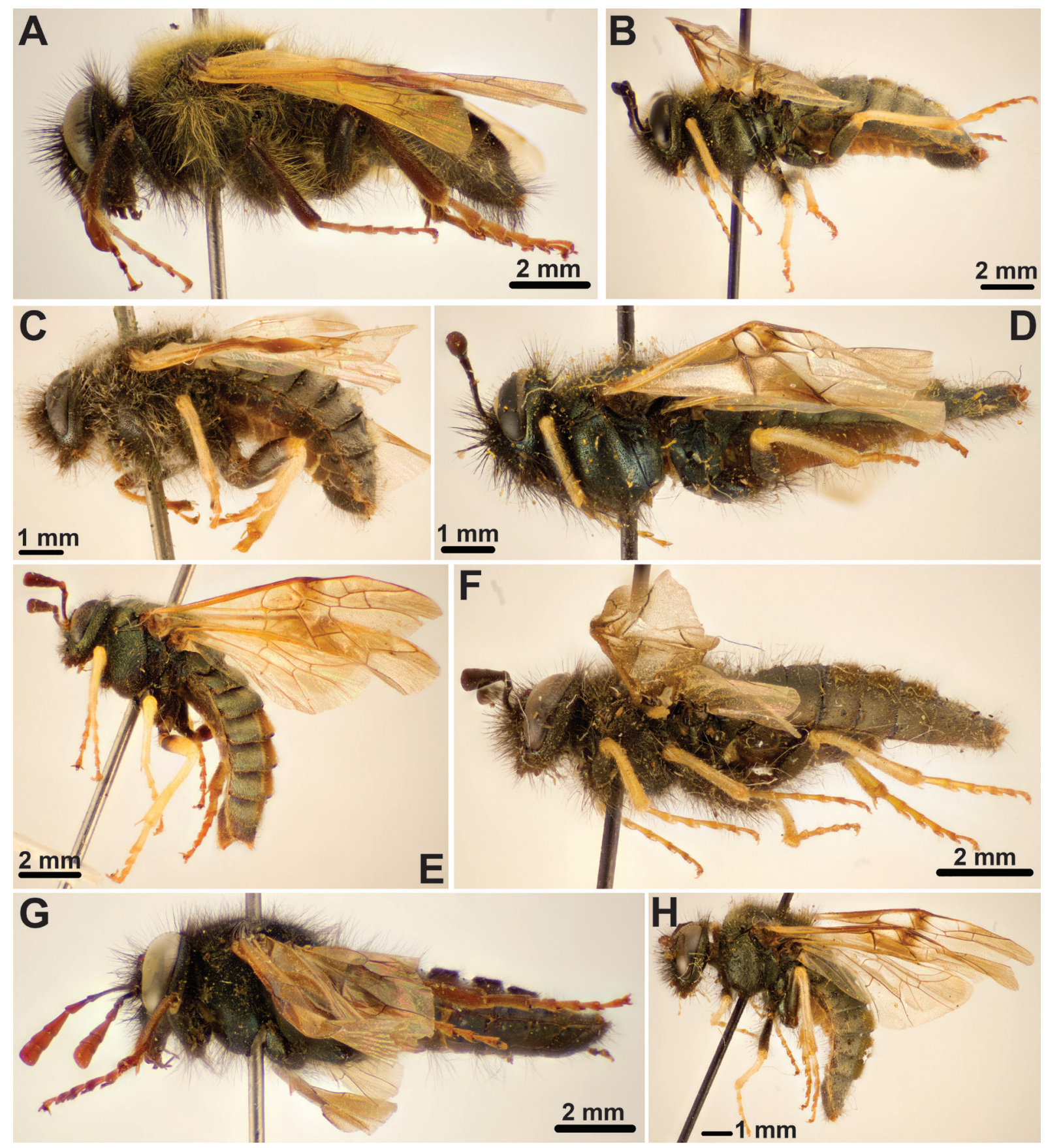

Fig. 4. Habitus lateral, males. A. Abia coreana (Takeuchi, 1927) (NSMT). B. Abia gribodoi Konow, 1895 (NMNH). C. Abia inflata (Norton, 1861) (NMNH). D. Abia kozhevnikovi Zhelochovtsev, 1924 (NRMS). E. Abia melanocera Cameron, 1899 (NRMS). F. Abia mutica Thomson, 1871 (NRMS). G. Abia sachalinensis (Takeuchi, 1931) (NSMT). H. Abia zhelochovtzevi (Gussakovskij, 1947) (NRMS). 

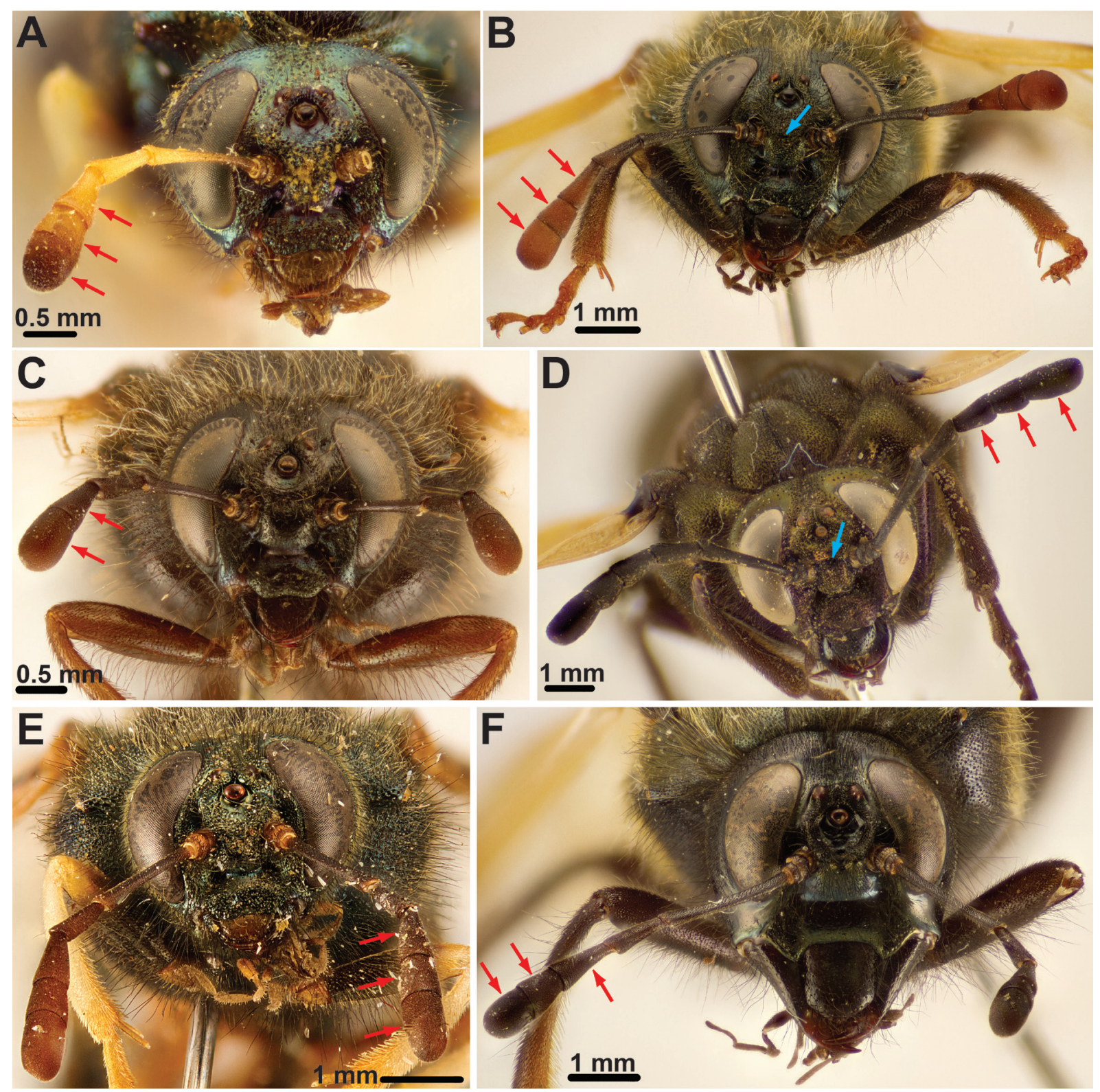

Fig. 5. Head, anterior view, females. A. Abia aurulenta Sichel, 1856 (NRMS). B. Abia coreana Takeuchi, 1927 (NSMT). C. Abia fasciata (Linnaeus, 1758) (NHMD). D. Abia imperialis Kirby, 1882 (NHMD). E. Abia niui Wei \& Deng, 1999 (NMNH). F. Abia relativa Rohwer, 1910 (NSMT). Red arrows = antennomeres in club; blue arrows $=$ intertorular groove. 


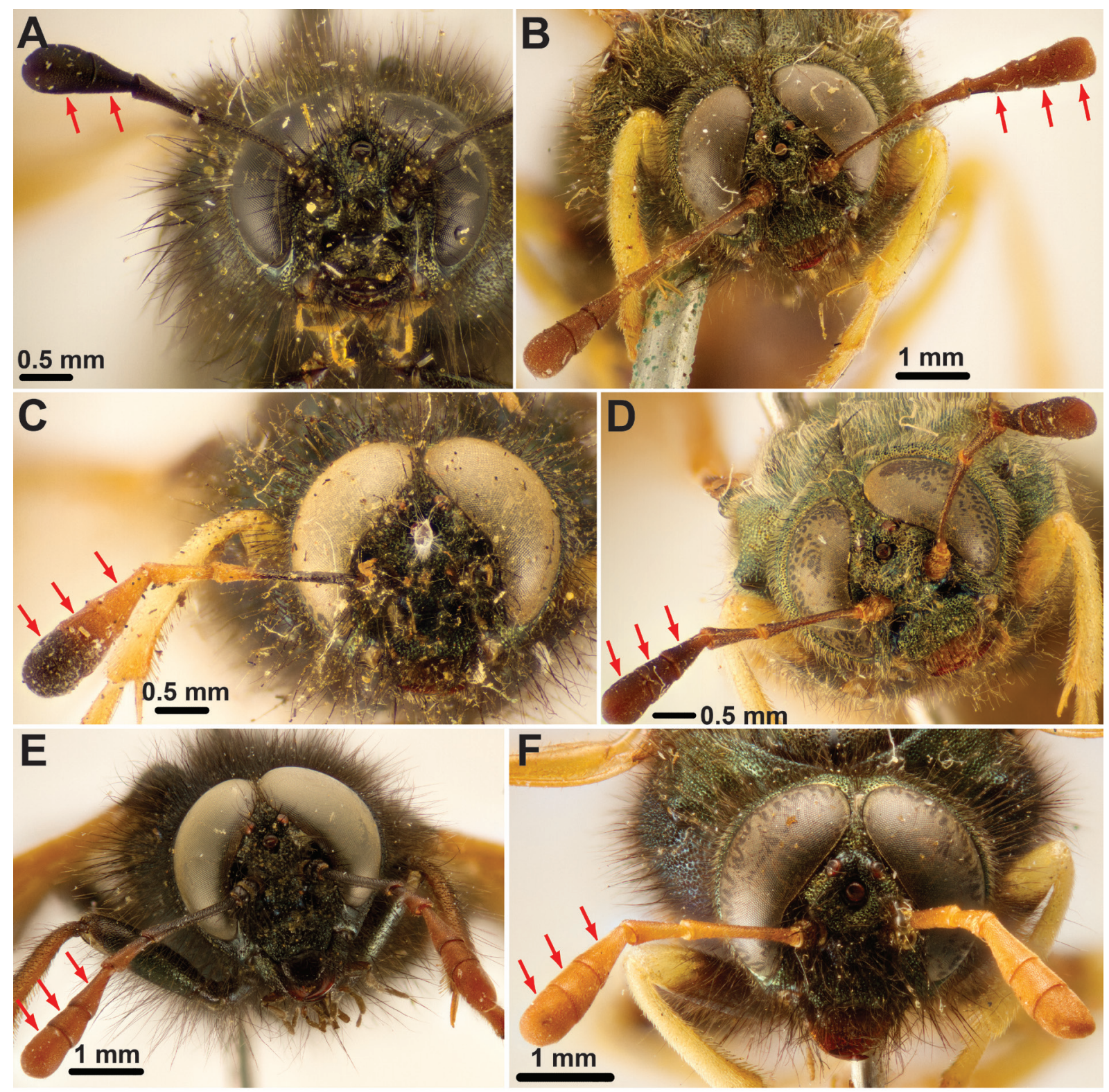

Fig. 6. Head, anterior view, males. A. Abia americana (Cresson, 1880) (NMNH). B. Abia berezowskii Semenov, 1896 (NRMS). C. Abia fulgens Zaddach, 1863 (NHMD). D. Abia melanocera Cameron, 1899 (NRMS). E. Abia sachalinensis Takeuchi, 1931 (NSMT). F. Abia sericea (Linné, 1767) (NSMT). Red arrows $=$ antennomeres in club. 
Abia infernalis Semenov, 1896 comb. rev.

Fig. 7

Abia infernalis Semenov, 1896: 173.

Allabia infernalis - Semenov \& Gussakovskij 1937: 5.

Diagnosis (based on male holotype)

Body color predominantly dark brown to black, non-metallic. Distance between eyes dorsally longer than diameter of median ocellus (Fig. 7C). Intertorular groove and epistomal sulcus well developed; clypeus slightly emarginate. Antenna with seven antennomeres (Fig. 7D). Hind tarsomere 1 shorter than tarsomeres 2+3 (Fig. 7B); tarsal claws with small subapical tooth some distance from apical tooth. Forewing without distinct transverse infuscate band (Fig. 7A). Abdominal terga 4-6 with hairy depressions; shallower depression without specialized hairs present on tergum 7 .

\section{Material examined}

\section{Holotype}

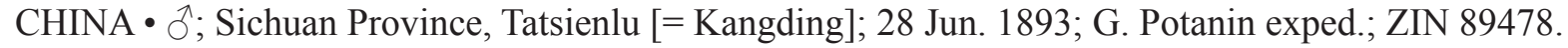

\section{Comments}

We only examined the holotype and are not aware of any other material of this species. The type has a body length of $13.3 \mathrm{~mm}$. The body is dark brown to black (Fig. 7A-B), as are the antennae and most of the legs basally; the extremities become less dark towards the apices, but there is no strong contrast. The labrum and maxillary and labial palps are pale brown. The fore wings are slightly infuscate anteromedially. The holotype generally is in good condition, although the left foreleg is missing tarsomeres 3-5.

Semenov \& Gussakovskij (1937) erected Allabia for Abia infernalis Semenov, 1896 and Allabia malaisei Semenov \& Gussakovskij, 1937, with the former as the type species. They justified this action as follows (bottom of p. 5, translated from French): "Having allowed the subdivision of the original genus Abia (Leach) ... in several genera (Abia Leach, Zaraea Leach, Orientabia Malaise), it is unavoidable ["indispensable"] to create a separate genus for Abia infernalis Sem[enov], since this species cannot be placed in any of the genera mentioned above." They then proceeded to briefly diagnose Allabia as having a similar (i.e., emarginated) clypeus as in Orientabia, but with a longer distance between the eyes dorsally, whereas it differs from Abia and Zaraea in the configuration of the clypeus and the tarsal claws.

In the phylogenetic analyses (see below) we show that Abia infernalis is nested deeply within Abiinae. In the case of Allabia, it seems that the genus has been based on the examination of only two male specimens, the holotypes of Abia infernalis and Allabia malaisei, respectively. To the best of our knowledge, no additional specimens have been associated with these two species or with Allabia since Semenov \& Gussakovskij (1937), although the genus is occasionally included in keys to Asian or Holarctic cimbicid genera (Wei et al. 2012). For these reasons, we treat Allabia Semenov \& Gussakovskij, 1937 as a synonym of Abia Leach, 1817.

\section{Discussion}

The monophyly of Abiinae is primarily supported by the configuration of the eyes, converging dorsally above the ocelli in both sexes, especially in the males, and having a longitudinal carina medially on abdominal tergum 1 (with a few reversals, e.g., A. kozhevnikovi). More dubious, even if unique within Cimbicidae, is the presence of an epistomal sulcus and the absence of a ventral head sclerotization; these traits might be retained plesiomorphies (see Vilhelmsen 2019). An additional putative autapomorphy 

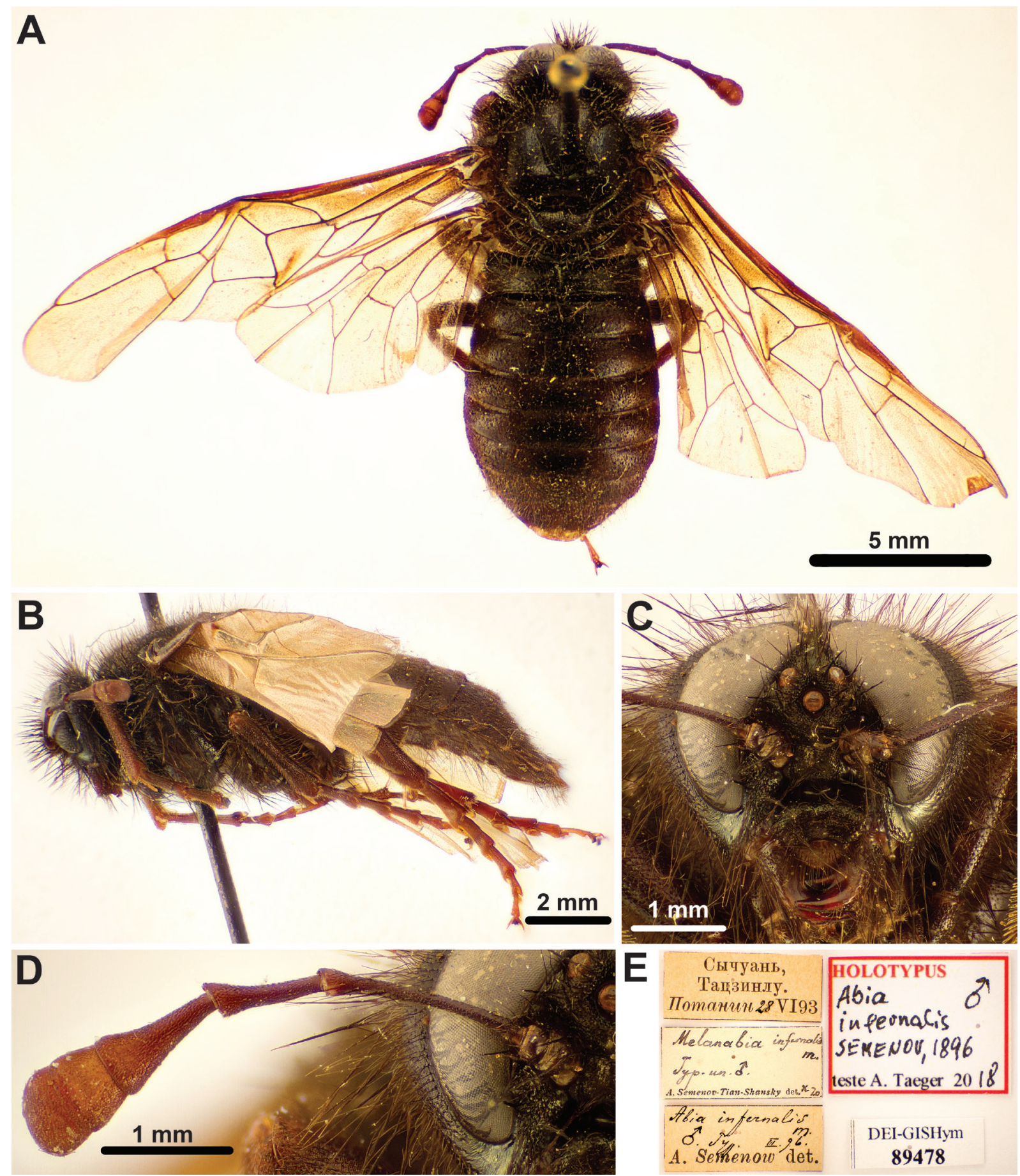

Fig. 7. Abia infernalis Semenov, 1896 comb. rev.. Holotype, male (ZIN). A. Habitus, dorsal view. B. Habitus, lateral view. C. Head, anterior view. D. Right antenna. E. Labels. 
not previously included is the presence of a transverse infuscate band in the fore wing (character 150:1; e.g., Fig. 1B). This is apparently a ground plan character for Abiinae observed in few other Cimbicidae; however, there are a number of reversals within the subfamily.

The fasciata group (A. akebii $+[$ A. fasciata + A. triangularis $]$ ) is supported by the presence of a white abdominal tergum 1 (character 113:1 [Fig. 1B]; paralleled in A. inflata). Conversely, the remainder of the Abiinae are supported by overall metallic body coloration (character 144:1 [Figs 1A, C-E, 2A-D]; reversed in Al. infernalis $+A$. kennicotti, as well as in A. inflata and A. marginata); all of these except A. aurulenta are supported by having depressions on the abdominal terga with hair patches in the males. Initially, only terga 4 to 6 have these patches (character 124:1; Fig. 2A-B), but in the sericea group they extend to tergum 7 as well (character 124:2; Fig. 2D); this group is also supported by having seven antennomeres (character 10:3 [Figs 5A-B, D-F, 6B-F]; paralleled in Al. infernalis [Fig. 7D] and A. akebii), i.e., three instead of two antennomeres in the club, the character originally used by Leach (1817) to define Abia.

All of the members of the sericea group except A. alutacea have bifid tarsal claws (character 85:1; paralleled in Al. infernalis, A. aurulenta and A. lonicerae) and most of them have an intertorular groove (character 146:1; reversed in A. iridescens and A. relativa; paralleled in the infernalis group [A. americana $+\{(A$. lewisii $+A$. metallica $)+($ Al. infernalis $+A$. kennicotti $)\}])$; at this node the length of the hind basitarsus also switches to become at least as long as the two following tarsomeres (character 84:1), but this is reversed in the node connecting the 'core Orientabia' $(([$ A. coreana + A. japonica $]+$ A. relativa $)+$ A. sachalinensis) to its sister group. The clade $A$. nitens $+(A$. berezowskii $+A$. melanocera $)$ has the eyes further apart dorsally than the diameter of the median ocellus in the males (character 145:1 [Fig. 6B, D]; paralleled in Al. infernalis [Fig. 7C]) and the fore wing with a longitudinal infuscate band along its anterior margin (character 106:1; Fig. 1C, E). The 'core Orientabia' clade has the ventral margin of the clypeus deeply incurved (character 4:1) and the hind tibia dark (character 149:0; reversed in female A. japonica; several parallelisms within Abiinae, see Fig. 8).

Some of the characters included here to elucidate Abiinae phylogeny seem to be useful in helping to delimit clades (e.g., number of antennomeres, number of tarsal claws, body coloration, $1^{\text {st }}$ abdominal tergal coloration, occurrence of depressions on the abdominal terga with hair patches; see above) even if they are rarely completely free from homoplasy. Others are highly variable (e.g., the coloration of antennae in both sexes) and, while potentially useful in developing identification keys to species, provide little but noise to the phylogenetic analysis.

The present analysis, including just over half the number of recognized species of Abiinae, has the most comprehensive taxon sampling of any published phylogeny of the subfamily. However, like previous attempts, it falls far short of producing a robust phylogenetic hypothesis that might serve as a base for developing a more stable definition of genera within Abiinae. Even the inclusion of additional characters traditionally used in classification schemes that were missing from Vilhelmsen (2019) have not provided substantially better resolution and support for individual clades. One may hope that future studies will be more successful in this regard. More specifically, a comprehensive molecular data set for Cimbicidae and Abiinae in particular has yet to be developed. Apart from Liston et al. (2014) who included about a dozen Palearctic species, sampling of Abiinae so far has been somewhat ad hoc for analyses focused on unravelling symphytan relationships at the family and superfamily level (e.g., Malm \& Nyman 2015). The recently published molecular analyses by Yan et al. (2019, Fig. 13) while having a substantial representation of Cimbicidae, only included the CO1 gene and primarily sampled Cimbicinae and Coryninae, with only three species of Abia being included.

Defining genera within Abiinae is also problematic because of the number of taxa that have already been proposed and the variability of the characters that have been used to define them. Using the 
topology in Fig. 8 as the starting point, one might define Abia s. str. as the sericea group, Allabia as the infernalis group and Zaraea as the fasciata group; only the former can be convincingly characterized morphologically (presence of seven antennomeres and depressions with hair patches on abdominal terga 4-7 of males). Recognizing the 'core Orientabia' which is nested within the sericea group as a genus would require further splitting of the latter, depending on exactly where A. sericea is placed; this taxon behaves somewhat as a rogue within the sericea group, further complicating the implementation of a natural genus-level classification. Such a scheme still would leave the substantial basal polytomy of taxa within Abiinae unaccounted for; resolving this would probably require the recognition of additional genera.

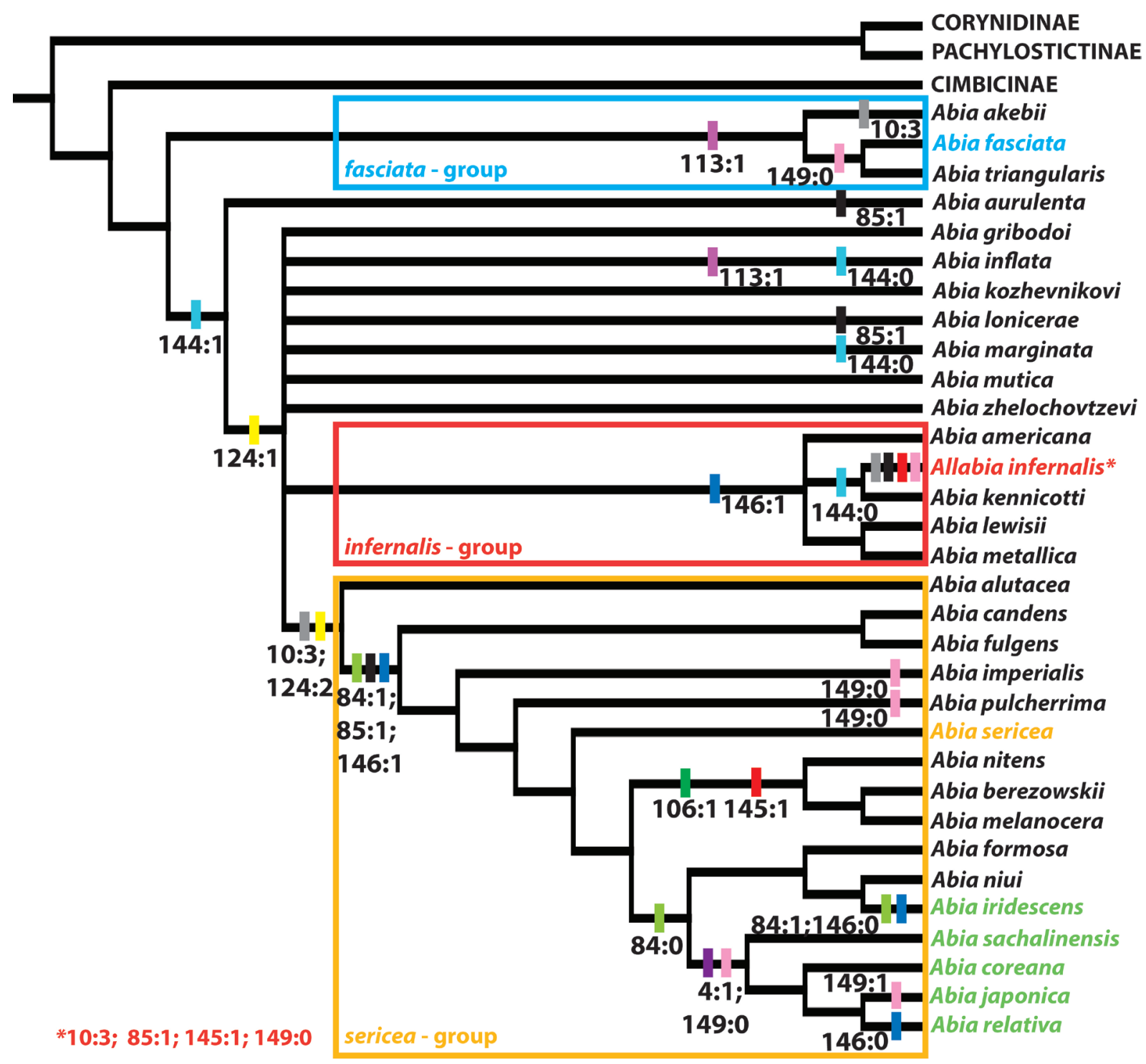

Fig. 8. Topology of Abiinae after IW analysis with $k=7$. Other subfamilies of Cimbicidae collapsed, outgroup not shown. Allabia infernalis Semenov, 1896 marked with red; taxa placed in Orientabia Malaise, 1934 according to Taeger et al. (2010) marked with green. Abia fasciata (Linnaeus, 1758) (type species of Zaraea) marked with blue, Abia sericea (Linné, 1767) (type species of Abia) marked with yellow. Selected characters are mapped on the tree, see Discussion for further explanation. 
The results of our analyses clearly do not provide a solid base for defining multiple genera within Abiinae. The failure to retrieve a topology that supports the previously proposed genera probably reflects the lack of congruence among the characters that have previously been used to define genera in Abiinae and included in the analyses here. Instead of providing a consistent pattern, the characters display conflict; constructing a classification based on these will result in genera being assemblages of species defined by random combinations of variable characters rather than natural groups supported by true synapomorphies. If this strategy is adopted for classification, it is likely to lead to a proliferation of poorly defined genera within the subfamily as new species with character combinations previously not encountered are described. Abiinae on the other hand is consistently retrieved and easily recognized (see above and Vilhelmsen 2019). With around 60 described species worldwide, this is not a large group and to ensure taxonomic stability in both the short and the long term, we recommend recognizing only Abia within the subfamily. If it is considered desirable to name clades within this genus, it can be handled more informally at the species group level.

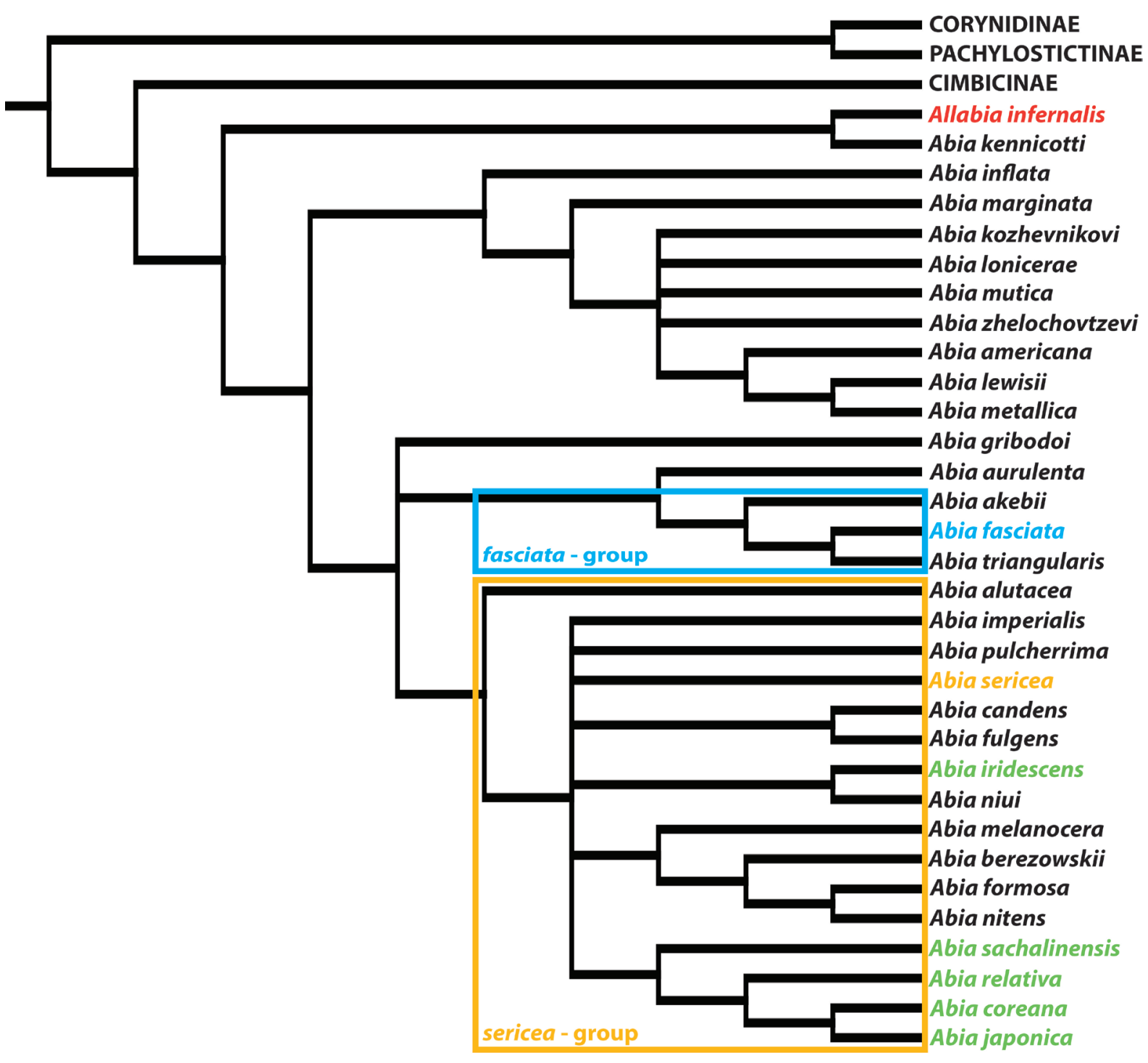

Fig. 9. Topology of Abiinae after IW analysis with $k=15$. Other subfamilies of Cimbicidae collapsed, outgroup not shown. Allabia infernalis Semenov, 1896 marked with red; taxa placed in Orientabia Malaise, 1934 according to Taeger et al. (2010) marked with green. Abia fasciata (Linnaeus, 1758) (type species of Zaraea) marked with blue, Abia sericea (Linné, 1767) (type species of Abia) marked with yellow. 


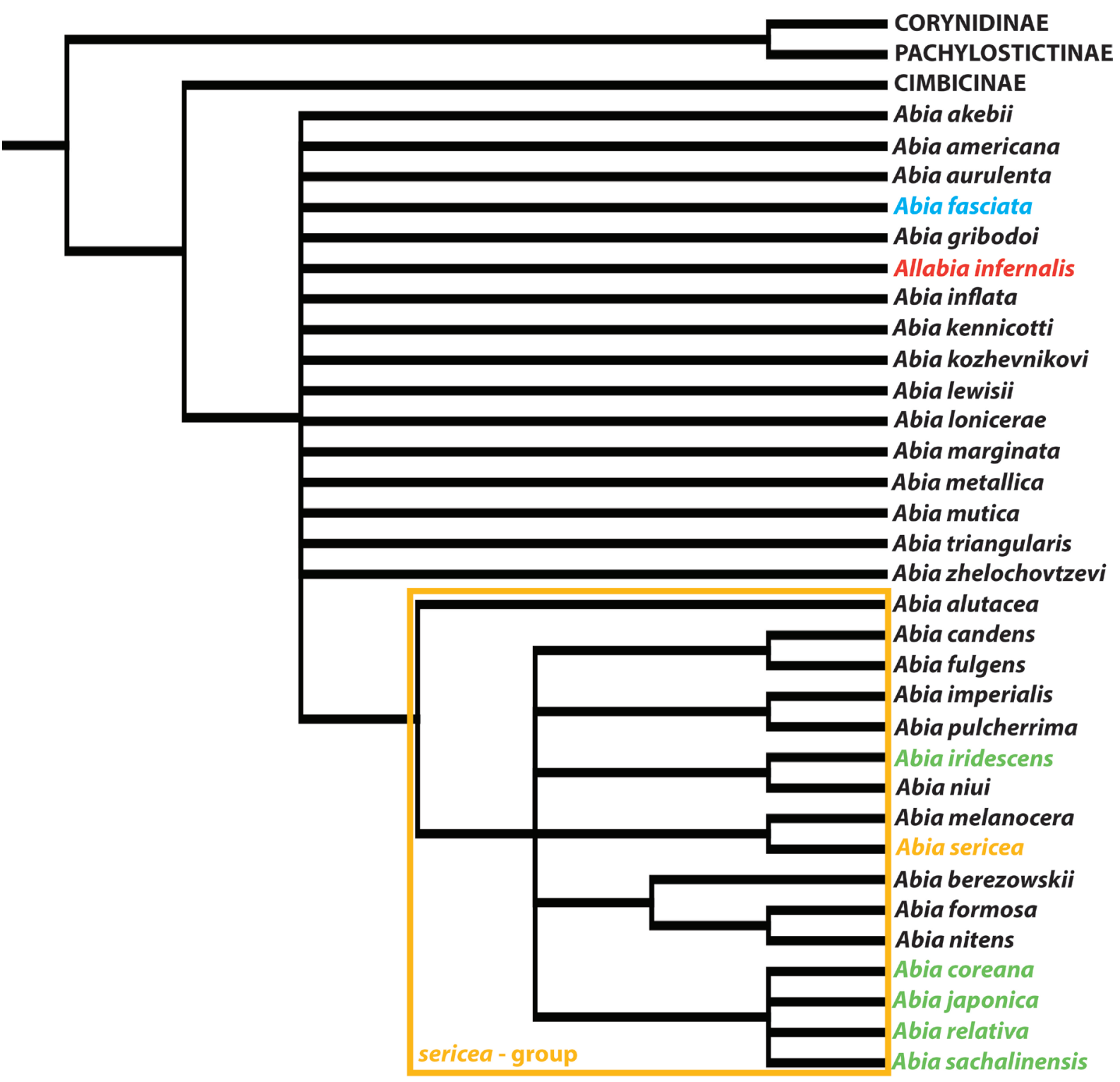

Fig. 10. Topology of Abiinae after EW analysis. Other subfamilies of Cimbicidae collapsed, outgroup not shown. Allabia infernalis marked with red, taxa placed in Orientabia Malaise, 1934 according to Taeger et al. (2010) marked with green. Abia fasciata (Linnaeus, 1758) (type species of Zaraea) marked with blue, Abia sericea (Linné, 1767) (type species of Abia) marked with yellow. 


\section{Acknowledgements}

Sergey Belokobylskij (ZIN) and Alexey Solodovnikov (NHMD) helped providing access to the holotype of Abia infernalis. Additional material was made available by Agnièle Touret-Alby (MNHN), David R. Smith (NMNH), Felipe Vivallo (MNRJ), Hege Vårdal (NRMS), Jane Costa (IOC) and Suzanne Ryder (NHMUK). Three anonymous reviewers provided helpful comments on an earlier version of the paper.

\section{References}

Benson R.B. 1946. The honeysuckle sawfly, Zaraea lonicerae (L.) comb. nov. (Hym., Cimbicidae). The Entomologist's Monthly Magazine 82 (7): 101-102.

Benson R.B. 1951. Handbooks for the Identification of British Insects. Vol. 4, part 2a: Symphyta (except Tenthredinidae). Hymenoptera. Royal Entomological Society of London, London.

Blank S.M., Taeger A., Liston A.D., Smith D.R., Rasnitsyn A.P., Shinohara A., Heidemaa M. \& Viitasaari M. 2009. Studies toward a World Catalog of Symphyta (Hymenoptera). Zootaxa 2254: 1-96.

Goloboff P.A. \& Catalano S.A. 2016. TNT version 1.5, including a full implementation of phylogenetic morphometrics. Cladistics 32: 221-238. https://doi.org/10.1111/cla.12160

Goulet H. 1992. The genera and subgenera of the sawflies of Canada and Alaska. Hymenoptera: Symphyta. The Insects and Arachnids of Canada 20: 3-235.

Gussakovskij V.V. 1947. Insectes Hyménoptères, Chalastogastra 2. In: Pavlovsky E.N. \& Stackelberg A.A. (eds) Faune de l'URSS, Vol. 2: 1-235. Académie des Sciences de l'URSS, Moscow/Leningrad.

Hara H. \& Shinohara A. 2017. Taxonomic notes and new distribution and host plant records for sawflies and woodwasps (Hymenoptera, Symphyta) of Japan II. Bulletin of the National Museum of Nature and Science Series A (Zoology) 43: 53-69.

Hong Y.C. 1984. Fossil insects in the diatoms of Shanwang. Bulletin of the Tianjin Institute of Geology and Mineral Resources 8: 1-15. [In Chinese.]

Kangas E. 1946. Über die Gattung Abia Leach (Hym., Tenthredinidae) im Lichte ihrer europäischen Arten. Annales Entomologici Fennici 12: 77-122.

Konow F.W. 1887. Description de quelques espèces nouvelles de Tenthrédines et tableau analytique du genre Abia. Revue d'Entomologie 6: 1-5.

Leach W.E. 1817. The Zoological Miscellany. Being Descriptions of New or Interesting Animals Vol.3. R. \& A. Taylor, London.

Lee J.-W. \& Jung J.-C. 1999. Taxonomic review of the family Cimbicidae (Hymenoptera, Symphyta) from Korea. Insecta Koreana 16: 197-223.

Liston A. D., Savina H., Nagy Z. T., Sonet G. \& Boevé J.-L. 2014. Taxonomy, phylogeny and host plants of some Abia sawflies (Hymenoptera, Cimbicidae). Zootaxa 3821 (1): 125-132. https://doi.org/10.11646/zootaxa.3821.1.9

Maddison W.P. \& Maddison D.R. 2018. Mesquite: a modular system for evolutionary analysis. Version 3.6 [released 27 Jul. 2018]. Available from http://www.mesquiteproject.org.

Malaise R. 1934. Schwedisch-chinesische wissenschaftliche Expedition nach den nordwestlichen Provinzen Chinas unter Leitung von Dr. Sven Hedin und Prof. Sü Ping-Chang. Insekten gesammelt vom schwedischen Arzt der Expedition Dr. David Hummel 1927-1930. 23. Hymenoptera. 1. Arkiv för Zoologi 27: 1-40. 
Malm T. \& Nyman T. 2015. Phylogeny of the symphytan grade of Hymenoptera: new pieces into the old jigsaw(fly) puzzle. Cladistics 31: 1-17.

Quinlan J. \& Gauld I.D. 1981. Handbooks for the Identification of British Insects. Vol. 4, part 2a: Symphyta (except Tenthredinidae). Hymenoptera. Royal Entomological Society of London, London.

Ross H.H. 1937. A Generic Classification of the Nearctic sawflies (Hymenoptera, Symphyta). Illinois Biological Monographs 15 (2), University of Illinois, Urbana. https://doi.org/10.5962/bhl.title.50339

Semenov A. 1891. Revisio Hymenopterorum Musei Zoologici Academiae Caesareae Scientarum Petropolitanae. II. Genus Abia (Leach). Bulletin de l'Académie Impériale des Sciences de St.-Pétersbourg, N.S. 2 (34): 509-517.

SemenovA. 1896. Revisio specierum eurasiaticarumgeneris Abia (Leach). Ezhegodnik "Zoologicheskago Muzeja Imperatorskoj Akademii Nauk" 1: 153-180.

Semenov A. \& Gussakovskij V.V. 1937. Note sur les représentants paléarctiques de la tribu des Abiini (Hymenoptera, Tenthredinidae). Konowia 16: 1-9.

Smith D.R. 1979. Suborder Symphyta. In: Krombein K.V., Hurd P.D. Jr., Smith D.R. \& Burks B.D. (eds) Catalog of Hymenoptera in America North of Mexico. Vol. 1: Symphyta and Apocrita (Parasitica): 3-137. Smithsonian Institution Press, Washington.

Taeger A. 1998. Bestimmungsschlüssel der Keulhornblattwespen Deutschlands (Hymenoptera: Cimbicidae). In: Taeger A. \& Blank S.M. (eds) Pflanzenwespen Deutschlands (Hymenoptera, Symphyta). Kommentierte Bestandsaufnahme: 193-205. Goecke \& Evers, Keltern.

Taeger A., Blank S.M. \& Liston A.D. 2010. World catalog of Symphyta (Hymenoptera). Zootaxa 2580: $1-1064$.

Taeger A., Liston A.D., Prous M., Groll E.K., Gehroldt T. \& Blank S.M. 2018. ECatSym - Electronic World Catalog of Symphyta (Insecta, Hymenoptera). Program version 5.0 (19 Dec. 2018), data version 40 (23 Sep. 2018). Senckenberg Deutsches Entomologisches Institut (SDEI), Müncheberg. Available from https://sdei.de/ecatsym/ [accessed 9 Jul. 2019].

Takeuchi K. 1939. A systematic study on the suborder Symphyta (Hymenoptera) of the Japanese Empire (II). Tenthredo 2: 393-439.

Viitasaari M. 1990. Sawflies 5. Argidae, Blasticotomidae and Cimbicidae. University of Helsinki, Department of Agricultural and Forest Zoology, Report No. 15, Helsinki. [In Finnish.]

Vilhelmsen L. 2019. Giant sawflies and their kin: morphological phylogeny of Cimbicidae. Systematic Entomology 44: 103-127. https://doi.org/10.1111/syen.12314

Wei M., Wu X., Niu G. \& Xin H. 2012. Rediscovery of Odontocimbex svenhedini Malaise (Hymenoptera: Cimbicidae) from China with description of the female and a key to Asian genera of Cimbicidae. Entomotaxonomia 34: 435-441.

Yan Y., Niu G., Zhang Y., Ren Q., Du S, Lan B. \& Wei M. 2019. Complete mitochondrial genome sequence of Labriocimbex sinicus, a new genus and new species of Cimbicidae (Hymenoptera) from China. PeerJ 7: e7853. https://doi.org/10.7717/peerj.7853

Zhang J.-F. 1989. Fossil Insects from Shanwang, Shandong, China. Shandong Science and Technology Publishing House, Jinan. [In Chinese.]

Zhelochovtsev A.N. [=Zhelohovcev A.N.] \& Zinovjev A.G. 1988. 27. Otrjad Hymenoptera Pereponchatokrylye Podotrjad Symphyta (Chalastogastra) - Sidjachebrjuhie. [27. Order Hymenoptera Wasps Suborder Symphyta (Chalastogastra) - Sawflies and woodwasps]. In: Zhelohovcev A.N., Tobias V.I. \& Kozlov M.A. (eds) Opredelitel' nasekomyh evropejskoj chasti SSSR. T. III. Pereponchatokrylye. 
Shestaja chast' (Opredeliteli po faune SSSR, izdavaemye Zoologicheskim institutom AN SSSR; Vyp. 158) [Key to the insects of the European part of the USSR. Vol. III. Hymenoptera. Sixth part. (Keys to the fauna of the USSR, edited by the Zoological Institute of the Academy of Sciences of the USSR; Vol. 158)]: 7-234. Nauka, Leningrad.

Zhelochovtsev A.N., Tobias V.I. \& Kozlov M.A. 1994. In: Medvedev G.S. (ed.) Keys to the Insects of the European Part of the USSR. Volume III: Hymenoptera. Part 6: Symphyta. Brill, Leiden.

Manuscript received: 27 August 2019

Manuscript accepted: 4 November 2019

Published on: 25 February 2020

Topic editor: Gavin Broad

Desk editor: Chloë Chester

Printed versions of all papers are also deposited in the libraries of the institutes that are members of the EJT consortium: Muséum national d'histoire naturelle, Paris, France; Meise Botanic Garden, Belgium; Royal Museum for Central Africa, Tervuren, Belgium; Royal Belgian Institute of Natural Sciences, Brussels, Belgium; Natural History Museum of Denmark, Copenhagen, Denmark; Naturalis Biodiversity Center, Leiden, the Netherlands; Museo Nacional de Ciencias Naturales-CSIC, Madrid, Spain; Real Jardín Botánico de Madrid CSIC, Spain; Zoological Research Museum Alexander Koenig, Bonn, Germany; National Museum, Prague, Czech Republic. 